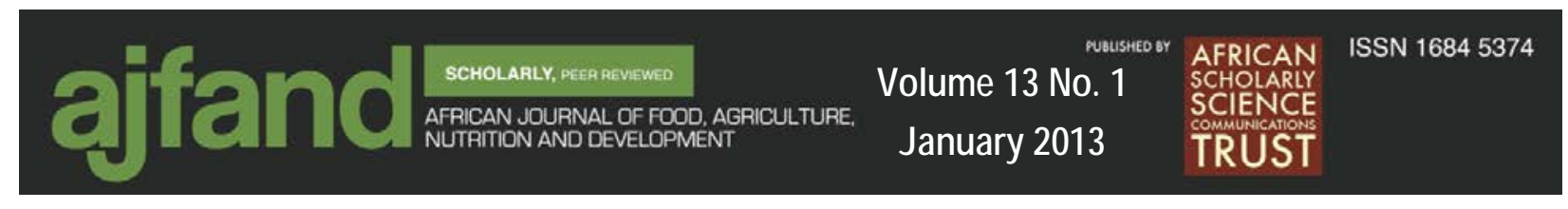

\title{
EVALUATING DIVERSITY AMONG KENYAN PAPAYA GERMPLASM USING SIMPLE SEQUENCE REPEAT MARKERS
}

\section{Asudi GO ${ }^{1}$, Ombwara FK $^{2}$, Rimberia FK $^{2}$, Nyende $A^{1}{ }^{1}$, Ateka $E^{2}$ and LS Wamocho ${ }^{3}$}

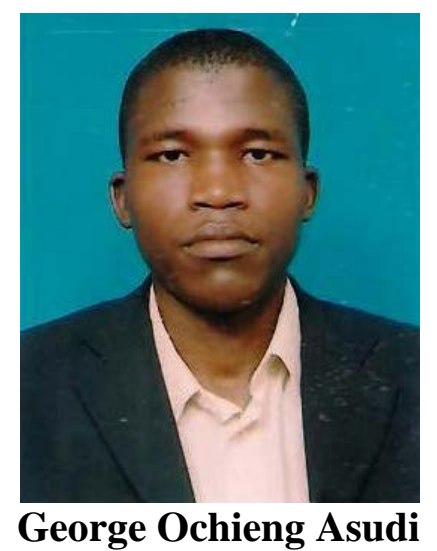

*Corresponding author email: gasudi@yahoo.com

${ }^{1}$ Institute for Biotechnology Research, Jomo Kenyatta University of Agriculture and Technology, P. O. Box 62000-00200, Nairobi, Kenya.

${ }^{2}$ Horticulture Department, Jomo Kenyatta University of Agriculture and Technology, P. O. Box 62000-00200, Nairobi, Kenya.

${ }^{3}$ Department of Sugar Technology, Masinde Muliro University of Science and Technology, P.O. Box 1900-5100 Kakamega, Kenya. 


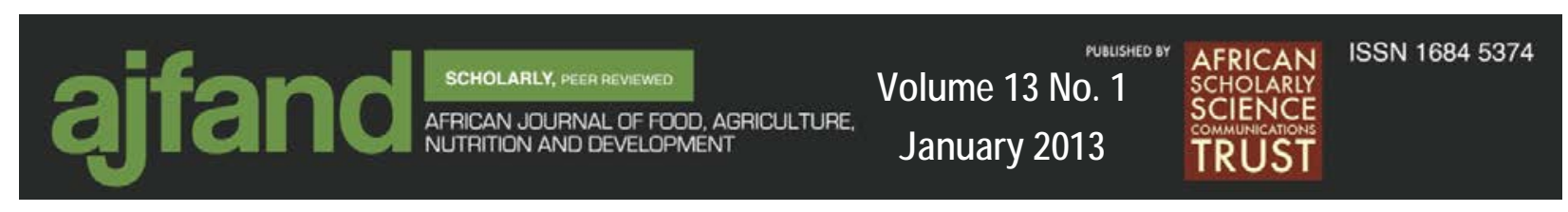

\section{ABSTRACT}

Papaya is an important fruit crop, produced in Kenya for local consumption and export. Despite a history of varietal introductions, no attempts concerned on developing varieties suited to Kenyan conditions have been documented. The objective of this study was to provide information on the diversity of germplasm available in Kenya, as a precursor to systematic plant breeding program. Forty two papaya accessions were collected from farmers' fields located in Coast, Rift Valley, Western, Nyanza, Central and Eastern provinces. Genetic diversity was determined using seven simple sequence repeat (SSR) markers, computing allelic richness and frequency, expected heterozygosity and cluster analysis. Results indicated that the markers were highly polymorphic among the accessions, with polymorphic information content (PIC) varying from 0.75 to 0.852 with an average of 0.81 . The genetic similarity among the 42 papaya accessions ranged from 0.764 to 0.932 with an average of 0.844 showing that most papaya accessions used in this study were closely related. About $96.9 \%$ of the pair-wise comparisons among papaya accessions exhibited genetic similarity greater than 0.802 , while less than $4 \%(3.1 \%)$ showed genetic similarity lower than 0.802 . The phylogenetic analysis grouped the 42 accessions into two main clusters A and B. Cluster A had four sub-clusters while cluster B had one cluster. Accessions from Coast, and some from Rift Valley Provinces, presented the highest variation, being scattered throughout the tree, with little or no differentiation from most accessions, whereas some accessions from Coast regrouped in clusters $A$ (iv) and $B$. The genetic differences among the accessions revealed by the formation of distinct clusters suggest significant genetic variability emanation from varying sources of the papaya germplasm in Kenya. Although the level of genetic diversity revealed by SSR markers in this study is sufficient to distinguish between breeding lines for varietal protection, the rather narrow genetic diversity demonstrated indicates the need to introduce new germplasm or use other techniques such as mutation and genetic engineering to provide breeding materials for the future improvement of papaya in Kenya.

Key words: Kenya, papaya, genetic diversity. 


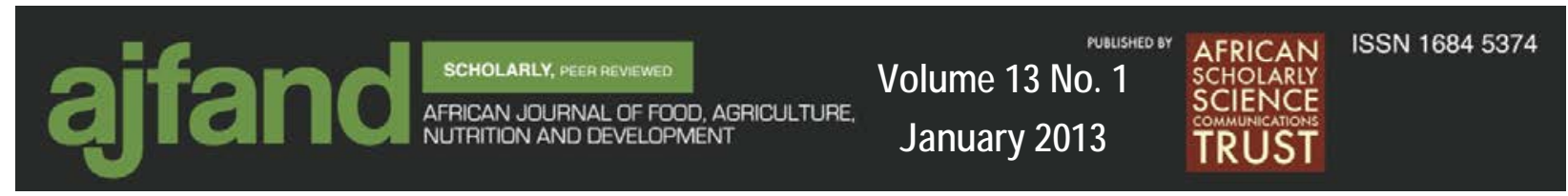

\section{INTRODUCTION}

Papaya (Carica papaya, L.) is a cosmopolitan tropical fruit tree, native to southern Mexico and neighboring Central America. It was distributed to the Caribbean and South-East Asia as a result of the Spanish exploration of the $16^{\text {th }}$ Century, from where it spread rapidly to India, the Pacific and Africa [1]. It can now be found distributed throughout the tropical and sub tropical regions of the world.

Approximately 7,207,534 metric tons of papaya fruit were produced worldwide in 2007 [2], placing it fourth in terms of world production of tropical fruit crops. In Kenya, the papaya is considered an important fruit crop, being produced both for local consumption and as an export crop [3]. Kenya's papaya production in 2007 was estimated at 86,000 metric tons [2] of which 4.7 metric tons were exported [4]. Reported constraints to papaya production in Kenya include the pest and diseases such as the Papaya Ring Spot Virus, difficulty in papaya seedling sex determination and the inadequate supply of suitable local planting material [5].

A host of papaya varieties developed in different parts of the world have been introduced to Kenya. Some of these include; the 'Solo' type papaya, developed in Hawaii [6]; 'Cavite', introduced from the Philippines, varieties '417' and '418', both of Indian origin, and the variety 'Kiru', introduced through Tanzania [3]. Anecdotal evidence suggests various commercial varieties originating from Asia and America are regularly imported as seed by commercial papaya growers in Kenya [5]. Despite these introductions, no attempts to maintain varietal distinctness, or develop varieties uniquely suited to Kenyan conditions have been documented. The open pollinating nature of papaya's reproductive process further lends itself to decreasing varietal purity from one generation to the next.

A related member of family Caricaceae is highland papaya (Vasconcellea spp) native to Colombia and Ecuador. In Kenya they perform well from 1500 meters above sea level but are of little commercial importance [5]. Some members of the genus reportedly possess desirable traits including high levels of proteolytic enzymes, cold tolerance and disease resistance that could be useful in breeding programmes for papaya improvement [7].

Papaya germplasm shows considerable phenotypic variation for many horticultural traits [8]. The different criteria that can be used to estimate genetic diversity include pedigree records, morphological traits and molecular markers [9]. Genetic diversity provides the basis for genetic improvement and information regarding the diversity of available germplasm. Despite the range in phenotypic variability [10] no recent attempts have been made to develop papaya lines specifically suited for the Kenyan conditions using locally available germplasm.

Microsatellite markers have been developed and can be successfully employed to determine the genetic relationships between papaya cultivars [11]. Since simple sequence repeats (SSR) are multi-allelic, they have a high potential for use in evolutionary studies, germplasm diversity, pedigree analysis, cultivar identification, 


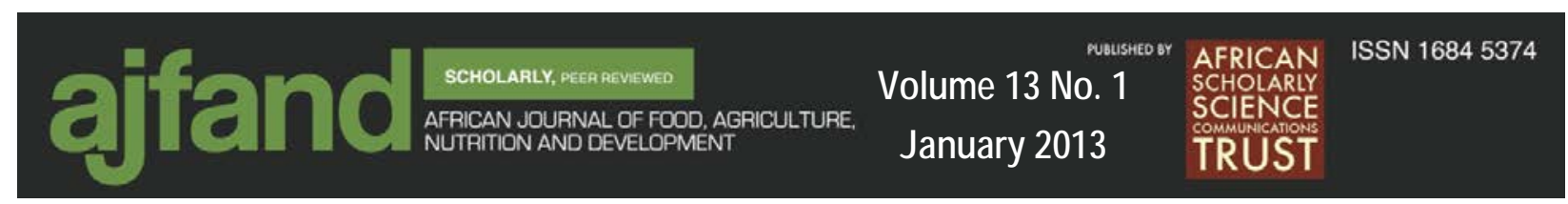

as well as genetic mapping studies. At present, microsatellites are one of the most promising molecular marker types able to identify or differentiate genotypes within a species. The fact that they are co-dominant markers, with high levels of polymorphism and are easy to handle make them extremely useful for many applications [9].

In this study we provide information on the diversity of germplasm available in Kenya, based on information garnered through molecular means of characterization. The results of the study form the basis for evaluation of the germplasm as a precondition for its use as breeding material for the improvement of Kenyan papaya.

\section{MATERIALS AND METHODS}

\section{Plant materials}

Forty two papaya accessions were collected from six main papaya producing provinces of Kenya (Table 1) between June 2008 and September 2008. A Global Positioning System (GPS) receiver (Magellan ${ }^{\circledR}$ Sport Trak Pro 2003) was used to determine the geographic coordinates for each sample site. The local or common names ascribed to the individual accessions were recorded as a reference to the material collected, and each accession was assigned a taxon code, based on its area of collection. The sex of each accession was determined by the floral morphology. Each collection comprised healthy, newly developed leaves excised from the apices of papaya growing in farmers' fields. The accessions were immediately placed in labeled polyethylene bags, stored in cool boxes containing dry ice at approximately $10^{\circ} \mathrm{C}$. The materials were subsequently transferred within $72 \mathrm{~h}$ to the laboratory and stored at $20^{\circ} \mathrm{C}$ for subsequent DNA analysis.

\section{Characterization of papaya using simple sequence repeats (SSR)}

Total genomic DNA of 42 papaya accessions was extracted from leaves using the method described by Doyle and Doyle [12]. The quantity and quality of the extracted DNA were determined by $1 \%$ agarose gel electrophoresis and spectrophotometry, respectively [13]. Seven labeled SSR primers (Table 2) were used for PCR amplification of the DNA samples. Each of the 7 pairs of SSR markers was successfully optimized and PCR reactions set up in a final volume of $20 \mu \mathrm{l}$ containing $10 \mathrm{ng}$ of genomic DNA, $2.0 \mu \mathrm{l}$ 10X PCR buffer with $\mathrm{MgCl}_{2}, 1.5 \mu \mathrm{l}$ of each $2.5 \mathrm{mM}$ dNTP, $5 \mathrm{U} / \mu \mathrm{l}$ Taq DNA polymerase and $0.5 \mu \mathrm{M}$ of each primer, one of them 5 '-end $\left(\gamma^{33}\right.$ P) radiolabeled and designed from the microsatellite library. Amplification was carried out using Gene-Amp PCR system 9700 (Applied Biosystems) in the following thermocycling scheme: denaturation at $94{ }^{\circ} \mathrm{C}$ for $5 \mathrm{~min}, 35$ cycles of $30 \mathrm{~s}$ at $94{ }^{\circ} \mathrm{C} ; 1$ min between $46{ }^{\circ} \mathrm{C}$ and $52{ }^{\circ} \mathrm{C}$ (Table 2); $45 \mathrm{~s}$ at $72{ }^{\circ} \mathrm{C}$; and a final elongation for $4 \mathrm{~min}$. at $72{ }^{\circ} \mathrm{C}$. The amplified DNA fragments were screened by capillary electrophoresis on the ABI 3730 genetic analyzer (Applied Biosystems). The GeneMapper v3.7 software was used to size peak patterns, using the internal Genescan ${ }^{\mathrm{TM}}-500 \mathrm{LIZ}^{\mathrm{TM}}$ size standard and Genotyper 3730 [14] for allele calling. 


\section{Simple sequence repeat analysis}

The total number of alleles, the number of common alleles with allelic frequencies of at least $5 \%$ and the polymorphism information content (PIC) values [9] were determined for each SSR marker. The SSR data was analyzed using the SIMQUAL (Similarity for Qualitative Data) routine to generate simple matching coefficients. These similarity coefficients were used to construct a dendrogram using the Unweighted Pair Group Method of Arithmetic averages (UPGMA) and employing the Sequential, Agglomerative, Hierarchical and Nested clustering (SAHN) from the Numerical Taxonomy and Multivariate Analysis (NTSYS-pc) version 2.1T [15].

\section{RESULTS}

\section{Genetic diversity of papaya using SSR primers}

The seven pairs of SSR primers used were polymorphic across all loci with an average polymorphic information index (PIC) of 0.81 . Marker mCpCIR2 had the highest PIC value of 0.852 whereas marker mCpCIR3 had the lowest PIC of 0.75 . A total of 24 alleles were detected. The number of alleles per locus ranged from 2 for mCpCIR10, mCpCIR8 and mCpCIR1 to 5 for mCpCIR18 and mCpCIR23 with an average of 3.42 (Table 3 ). The observed heterozygosity ranged from 0.48 to 0.88 with a mean of 0.62 across the seven SSR loci. The highest observed heterozygosity was in marker mCpCIR2 with a value of 0.88 whereas the lowest was 0.48 in marker mCpCIR1 (Table 3).

\section{Genetic variability within the 42 Papaya accessions}

The number of alleles within the 42 papaya accessions across the seven loci ranged from 8 to 18, with an average of 11.93. The highest number of alleles (18) was observed in accession KOS3, whereas the lowest (8) was observed in accession MIG9. These two accessions were collected in Coast province and appeared in different clusters. The allele frequencies ranged from 0.01 in all seven SSR markers used (i.e. mCpCIR1, mCpCIR2, mCpCIR3, mCpCIR8, mCpCIR10, mCpCIR18 and mCpCIR23) to 0.43 in the marker mCpCIR3. The highest allele frequency was observed in allele 191bp at locus mCpCIR3. The maximum size of 350bp was observed with primer mCpCIR10 whereas the lowest of 163bp was with primer pair mCpCIR3 (Table 3). The highest percentage of abundant alleles was observed in primer mCpCIR3 (41.86\%) whereas the lowest percentage of abundant alleles was observed in primer mCpCIR2 (24.72\%) (Table 3). None of the markers had rare alleles at $\leq 5 \%$. The lowest quality index was 0.3942 , observed in mCpCIR3, whereas the highest quality index of 0.5302 was in marker mCpCIR18 with an average being 0.4615 (Table 3).

The genetic similarity among the 42 papaya accessions ranged from 0.764 to 0.932 (Table 4) with an average of 0.844 showing that most papaya accessions used in this study were closely related (Table 4). About $96.9 \%$ of the pair-wise comparisons among papaya accessions exhibited genetic similarity greater than 0.802 , while less than $4 \%(3.1 \%)$ showed genetic similarity lower than 0.802 . There was strong genetic similarity between the papaya accessions IMA6 (Papayi) and MIG1 (Papayi) and

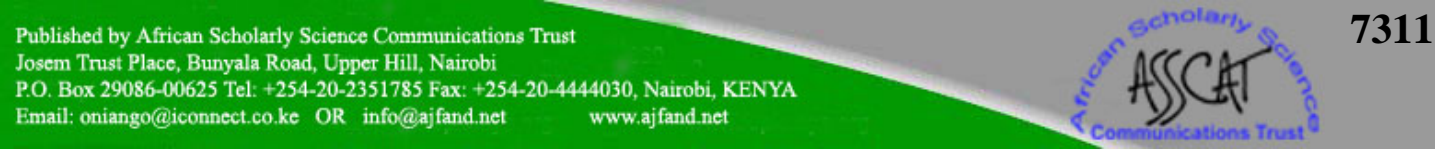




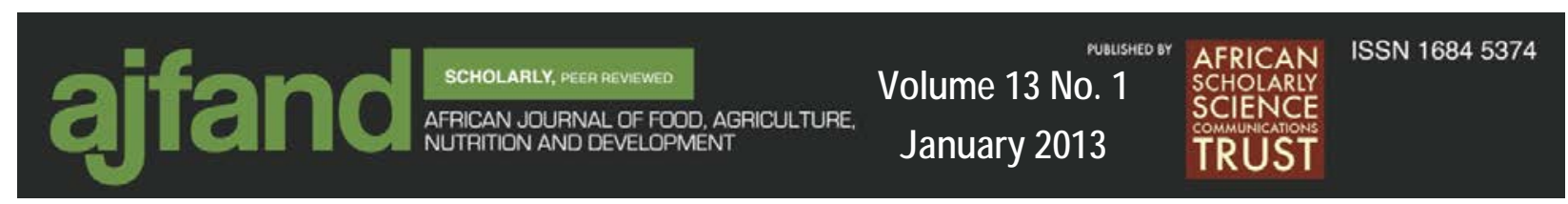

between JKU2 (Papayi) and KIZ3 (Apoyo) (Figure 1) all of which were classified in cluster A. KOS3 (Red-lady), MIG4 (Papayi) and IMA7 (Papayi) accessions showed the lowest similarities with the other accessions. KOS3 (Red-lady) showed the least similarity with all accessions with an average genetic similarity of 0.797 ranging from 0.764 to 0.845 . The two highland papayas (Vasconcellea spp) (JKU3 and MUT) had an average genetic similarity of 0.840 and clustered together.

\section{Phylogenetic analysis}

The UPGMA analysis grouped the 42 papaya accessions into two main clusters (Figure 1) namely A and B at the simple matching coefficient value of 0.81 . Further clustering of accessions arose at simple matching coefficient value of 0.93 . Cluster 'A' had 39 papaya accessions across all the six provinces. Cluster ' $B$ ' comprised three papaya accessions KOS3, MIG4 and IMA7 all of which were collected in Coast province. Cluster A, sub-cluster ' $\mathrm{i}$ ' comprised 25 accessions all of which were collected across the six provinces. This sub-cluster also had six accessions KOS4 (US), KOS2 (Red-lady), CHP1 (Honey dew), CHP2 (Solo), PKR1 (Kiru) and EMB1 (Sunrise) identified with specific varietal names. Cluster A, sub-cluster 'ii' was composed of two accessions (JKU3 and MUT) all of which were highland papayas collected in JKUAT (Central province) and Nakuru (Rift Valley province), respectively. Cluster A, sub-cluster 'iii' comprised 9 papaya accessions all of which were from five different provinces. Cluster A, sub-cluster 'iv' contained 3 papaya accessions all of which were collected from Coast province and were only identified as 'papayi' as the specific varietal names were not known. The dendrogram obtained with the SSR markers is indicative of a weak geographical structure (Figure 1). However, there are some little indications of a geographic component. Thus, three accessions clustered in group B and three accessions clustered in cluster A, subcluster 'iv' are all from Coast province. The Coast province accessions show the widest diversity, as they are scattered all over the dendrogram. 


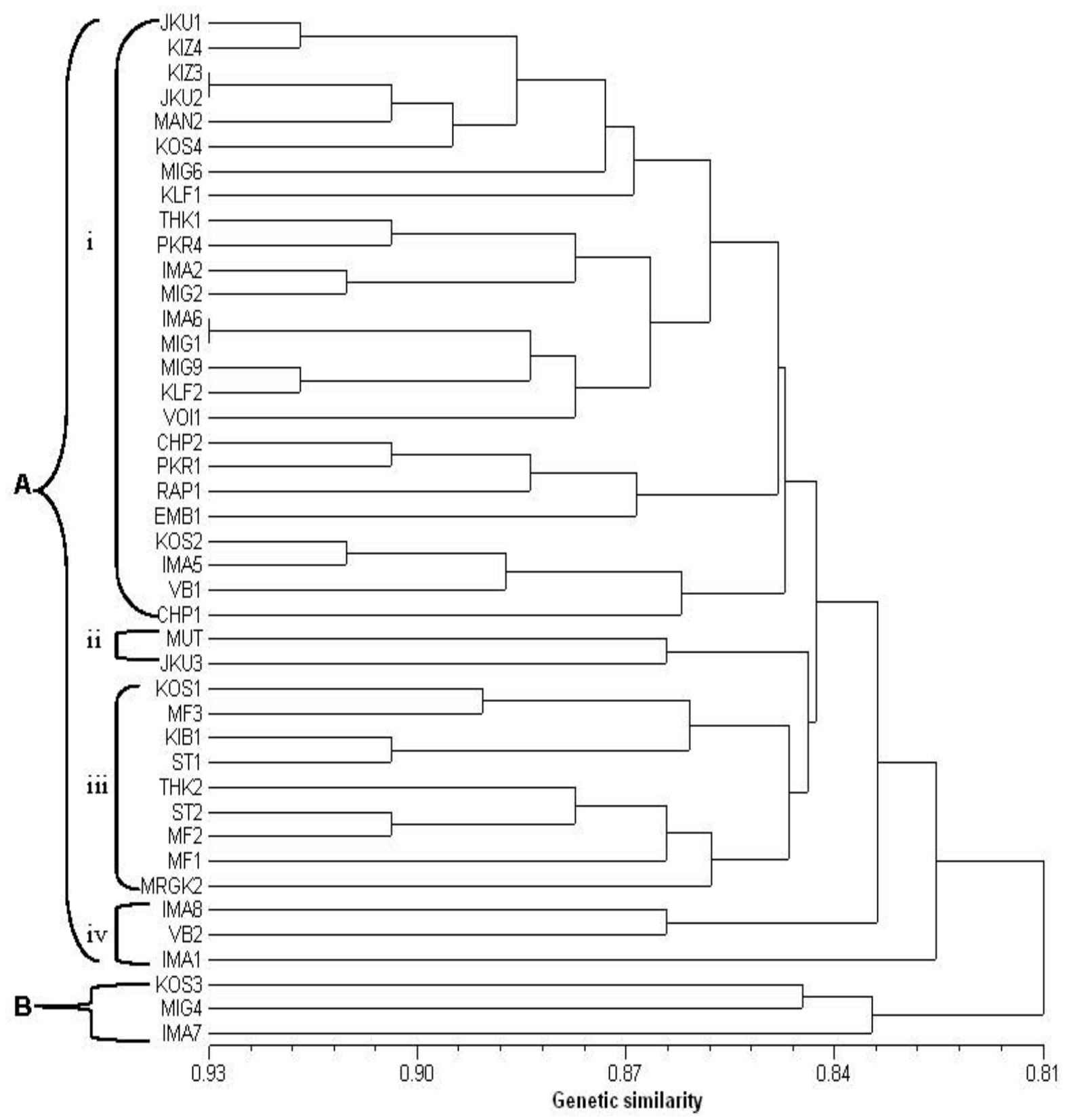

Figure 1. UPGMA dendrogram of 42 Kenyan papaya accessions based on genetic similarity matrix calculated from SSR markers. There were two main clusters, A with 39 accessions with four main sub-clusters and $B$ with 3 accessions. 


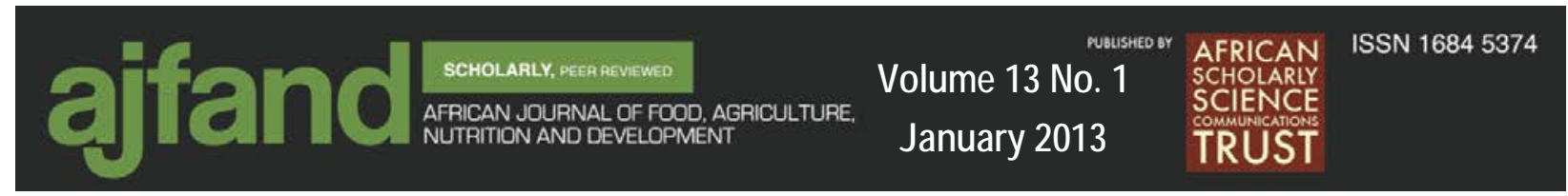

\section{DISCUSSION}

Assessment of genetic diversity and relationships among accessions is of interest not only for germplasm conservation but also for breeding purposes [16]. The present study is the first genetic characterization of Kenyan papaya germplasm using microsatellite markers. Microsatellite markers have previously shown high levels of genetic polymorphism in many important crops including Oryza sativa L. [17], Vitis vinifera [18], Helianthus annuus L. [19], Cucumis melon L. [20], cassava cultivars [21] and sweet potato [22]. The present study demonstrated that microsatellite markers were highly polymorphic in papaya accessions assessed in this study (Table 3). Microsatellite variation was clearly detected in the germplasm studied. The number of alleles varied greatly with all the markers having PIC values greater than 0.75. This amount of variation within each accession might best be explained by occasional outcrossing. Natural outcrossing in hermaphrodite papaya fields immediately adjacent to a potential source of contaminating pollen may affect about $5 \%$ of seed [23].

The level of microsatellite polymorphisms in papaya is relatively high considering the present study of 8 to 18 alleles per primer pair were amplified from the 42 papaya accessions. This may be due to cross pollination and wide geographical diversity from which the papaya accessions were collected. Moderate to high levels of heterozygosity were also observed in this study, and varied greatly across the seven loci, ranging from 0.48 to 0.88 . This may be due to the sex in papaya which is determined by a single gene with three alleles, in which males and hermaphrodites are heterogametic, while females are homogametic [24, 25]. These results indicate a high level of heterozygosity, which can be related to the plant's dioecy and to the low level of selection in papaya in Kenya.

Papaya (Carica papaya L. 2n=18) with a small genome size of $372 \mathrm{Mbp}$ [26], is a polygamous angiosperm with male, female and hermaphroditic forms [27, 28]. In this study, individual accessions were observed to contain between 2 and 5 alleles at any one locus. This is similar with the previous findings of between 2 and 8 alleles [11].

Pair-wise comparisons of genetic similarity among the Kenyan papaya accessions revealed limited genetic diversity which may be the consequence of inbreeding from a limited gene pool. This limited genetic variation detected among the accessions does not correspond to the wide range of morphological characteristics observed in the field [10]. These characteristics of agronomic importance are controlled by multiple genes, a few of which can significantly change plant morphological traits [29]. Most of these traits are sufficiently variable, and improvement consists of selecting desirable recombinants from segregating populations [23]. Our SSR study did not identify any of these, but could help point to related materials.

The genetic differences among the accessions revealed by their clustering into distinct groups suggest the presence of different sources of relationships among the papaya accessions. The dendrogram analysis (Figure 1) based on the seven SSR markers (Table 2) showed limited geographic delimitation of diversity. The germplasm from Coast, and to a lesser extent from Rift Valley, presented the highest degree of 


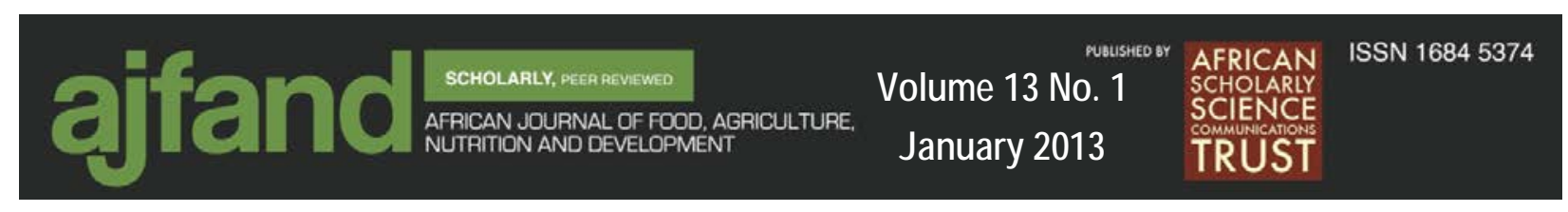

diversity, with little or no differentiation from most remaining accessions. Generally, the relationships among accessions in the cluster could be attributed to their diversity, geographical locations and also due to exchange of plant genetic resources among farmers within and between the provinces.

\section{CONCLUSION}

The results of this study provide estimates on the level of genetic variation among accessions that can be used in papaya germplasm management, varietal protection and improvement. The estimates of genetic similarity are particularly useful in choosing widely divergent parents with desirable traits for genetic mapping and selection. However, the limited genetic diversity demonstrated in this study indicates the need for the introduction of new papaya cultivars or use of other techniques such as mutations and genetic engineering to provide breeding materials for the future improvement of papaya in Kenya.

\section{ACKNOWLEDGEMENT}

The authors wish to thank Research, Production and Extension (RPE) division of Jomo Kenyatta University for Agriculture and Technology for funding the research. 
Table 1: Papaya accessions collected in Kenya and subjected to molecular analysis

\begin{tabular}{|c|c|c|c|c|c|}
\hline Accessions & $\begin{array}{l}\text { Cultivar/ } \\
\text { local name }\end{array}$ & Sexual type & Province & District & Elevation (masl) \\
\hline KIB1 & Papayi & Hermaphrodite & Central & Kirinyaga & 1431 \\
\hline JKU1 & Papayi & Hermaphrodite & Central & Thika & 1525 \\
\hline JKU2 & Papayi & Female & Central & Thika & 1525 \\
\hline JKU3 & Papayi/ vc & Hermaphrodite & Central & Thika & 1525 \\
\hline KLF1 & Papayi & Female & Coast & Kilifi & 25 \\
\hline KLF2 & Papayi & Hermaphrodite & Coast & Kilifi & 25 \\
\hline KOS1 & US & Hermaphrodite & Coast & Kilifi & 12 \\
\hline KOS2 & Redlady & Hermaphrodite & Coast & Kilifi & 12 \\
\hline KOS3 & Sunrise & Female & Coast & Kilifi & 12 \\
\hline KOS4 & US & Hermaphrodite & Coast & Kilifi & 12 \\
\hline MIG1 & Papayi & Female & Coast & Kilifi & 12 \\
\hline MIG2 & Papayi & Female & Coast & Kilifi & 12 \\
\hline MIG4 & Papayi & Female & Coast & Kilifi & 12 \\
\hline MIG6 & Papayi & Female & Coast & Kilifi & 12 \\
\hline MIG9 & Papayi & Hermaphrodite & Coast & Kilifi & 12 \\
\hline ST1 & Papayi & Female & Coast & Kilifi & 37 \\
\hline ST2 & Papayi & Female & Coast & Kilifi & 37 \\
\hline IMA1 & Papayi & Hermaphrodite & Coast & Taita & 613 \\
\hline IMA2 & Papayi & Hermaphrodite & Coast & Taita & 613 \\
\hline IMA5 & Papayi & Male & Coast & Taita & 613 \\
\hline IMA6 & Papayi & Female & Coast & Taita & 613 \\
\hline
\end{tabular}




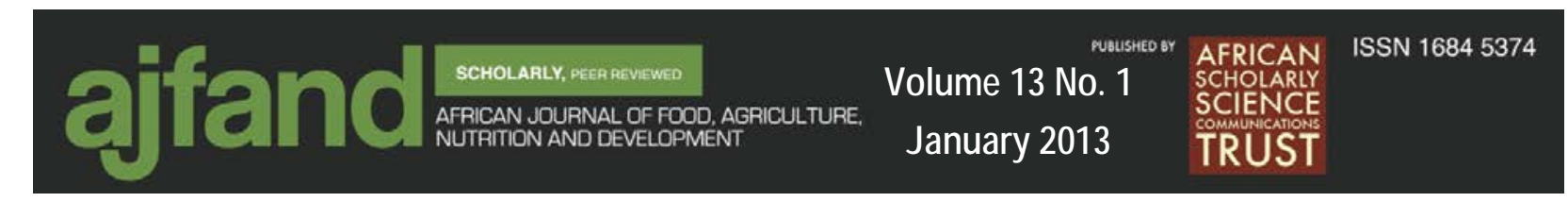

\begin{tabular}{|c|c|c|c|c|c|}
\hline IMA7 & Papayi & Female & Coast & Taita & 613 \\
\hline IMA8 & Papayi & Hermaphrodite & Coast & Taita & 613 \\
\hline MAN2 & Papayi & Female & Coast & Taita & 552 \\
\hline VOI1 & Papayi & Female & Coast & Taita & 582 \\
\hline EMB1 & Sunrise & Hermaphrodite & Eastern & Embu & 1488 \\
\hline MF1 & Mountain & Female & Eastern & Kirinyaga & 1124 \\
\hline MF2 & Local & Hermaphrodite & Eastern & Kirinyaga & 1124 \\
\hline MF3 & Mountain & Male & Eastern & Kirinyaga & 1124 \\
\hline THK1 & Local & Female & Eastern & Tharaka & 891 \\
\hline THK2 & Local & Male & Eastern & Tharaka & 891 \\
\hline KIZ3 & Aроуо & Female & Nyanza & Rongo & 1449 \\
\hline KIZ4 & Ароуо & Female & Nyanza & Rongo & 1449 \\
\hline RAP1 & Apoyo & Female & Nyanza & Rongo & 1295 \\
\hline MRGK2 & Sunrise solo & Hermaphrodite & Rift Valley & Baringo & 1025 \\
\hline PKR1 & Kiru & Female & Rift Valley & Baringo & 1011 \\
\hline PKR4 & Papayi & Female & Rift Valley & Baringo & 1011 \\
\hline CHP1 & Honey dew & Female & Rift Valley & Keiyo & 1232 \\
\hline CHP2 & Solo & Hermaphrodite & Rift Valley & Keiyo & 1232 \\
\hline MUT & Papayi/ vc & Hermaphrodite & Rift Valley & Nakuru & 1686 \\
\hline VB1 & Papayi & Female & Western & Taita & 589 \\
\hline VB2 & Papayi & Hermaphrodite & Western & Taita & 589 \\
\hline
\end{tabular}

Key

Vc - Vasconcellea spp 


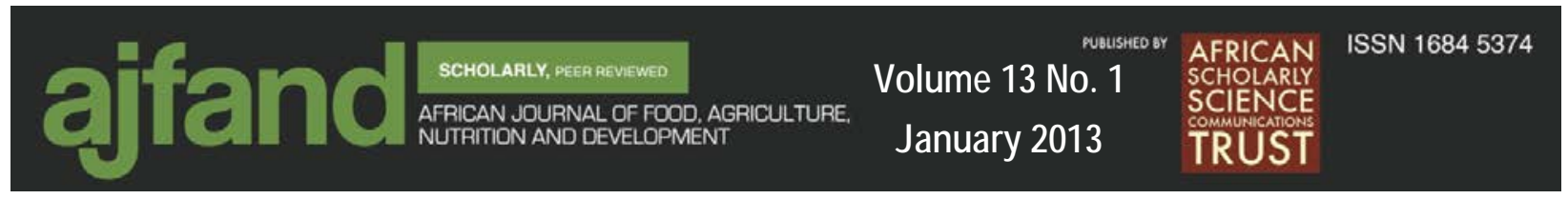

Table 2: Microsatellite primers used in the PCR amplification of the DNA samples of the papaya accessions

\begin{tabular}{|c|c|c|c|c|c|c|}
\hline $\begin{array}{l}\text { Marker } \\
\text { name }\end{array}$ & Dye & Forward primers 5'-3' & Reverse primers 3'-5' & Repeat motif & $\begin{array}{l}\text { Tm } \\
\left({ }^{\circ} \mathrm{C}\right)\end{array}$ & $\begin{array}{l}\text { Expected } \\
\text { allele size }\end{array}$ \\
\hline mCpCIR1 & PET & GCATTACTTATCATCGTCC & CTATCCTTGGCGTCTT & $(\mathrm{CT})_{18} \ldots(\mathrm{GA})_{3}$ & 48 & $314-364$ \\
\hline mCpCIR2 & PET & GTCTATCTACСТCССА & GAGTGTTATCATAGTCTACA & $(\mathrm{TC})_{24}$ & 52 & $260-284$ \\
\hline mCpCIR3 & NED & GAACTCACCTACACGAACT & ACTTCTACCACCGGC & $(\mathrm{TC})_{14}$ & 50 & $188-210$ \\
\hline mCpCIR8 & 6FAM & ATGGCTGAAGACAACTC & CTCAATAGCCCAATAACA & $(\mathrm{CT})_{20} \ldots(\mathrm{AC})_{5}$ & 46 & 283-293 \\
\hline mCpCIR10 & VIC & CAGCAGAAAACAAGGG & GGGTTCCGGTTTAGTT & $(\mathrm{TA})_{4} \ldots(\mathrm{AG})_{18}$ & 46 & $341-349$ \\
\hline mCpCIR18 & NED & ATGGGATTTTAGAGGTG & GTATGAGGGAATGGAAA & $(\mathrm{CT})_{9} \ldots(\mathrm{CT})_{9}$ & 50 & 291-295 \\
\hline mCpCIR23 & NED & CGCATTGTTATTGACT & ACCTACAGGGCCTAC & $(\mathrm{TC})_{8}$ & 50 & 281-283 \\
\hline
\end{tabular}

Source: Ocampo et al. [11]

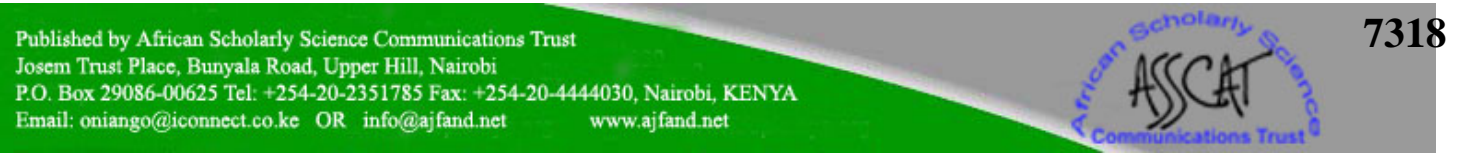




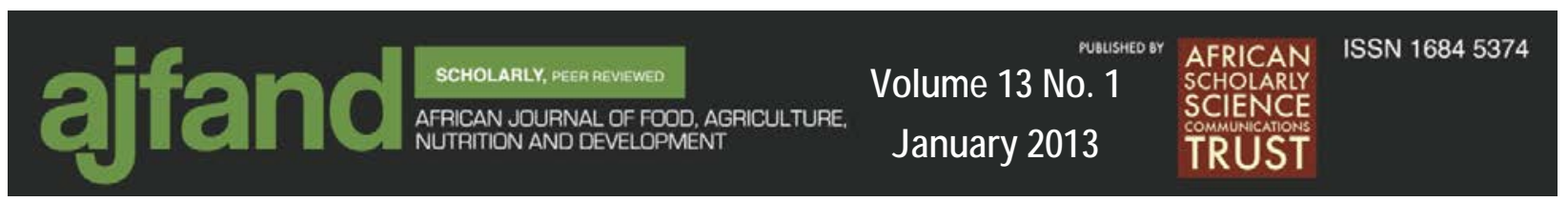

Table 3: Polymorphisms detected by seven SSR markers in 42 Kenyan papaya accessions

\begin{tabular}{|c|c|c|c|c|c|}
\hline Marker name & $\begin{array}{l}\text { Total no. of } \\
\text { alleles }\end{array}$ & $\begin{array}{c}\text { Allele size } \\
\text { range }\end{array}$ & $\begin{array}{l}\text { Abundant allele } \\
\qquad(>5 \%)\end{array}$ & ${ }^{\text {a }}$ PIC values & bobserved heterozygosity \\
\hline mCpCIR1 & 2 & $313-342$ & 30.95 & 0.822 & 0.48 \\
\hline mCpCIR2 & 4 & $242-300$ & 24.72 & 0.852 & 0.88 \\
\hline mCpCIR3 & 4 & $163-211$ & 41.86 & 0.750 & 0.62 \\
\hline mCpCIR8 & 2 & 283- 300 & 28.57 & 0.816 & 0.60 \\
\hline mCpCIR10 & 2 & 337- 350 & 28.57 & 0.846 & 0.64 \\
\hline mCpCIR18 & 5 & 288- 305 & 33.33 & 0.804 & 0.55 \\
\hline mCpCIR23 & 5 & 271- 293 & 34.04 & 0.791 & 0.57 \\
\hline Mean & 3.42 & & 31.71 & 0.810 & 0.62 \\
\hline
\end{tabular}

${ }^{\mathrm{a}} \mathrm{PIC}=1-\sum\left(\mathrm{pi}^{2}\right)$ where Pi is the frequency of the $\mathrm{i}^{\text {th }}$ allele detected

${ }^{\mathrm{b}}$ frequency at which heterozygous individuals occur in a population at a given locus.

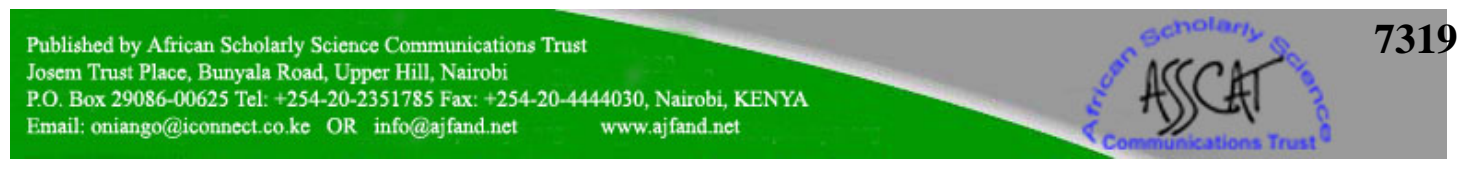




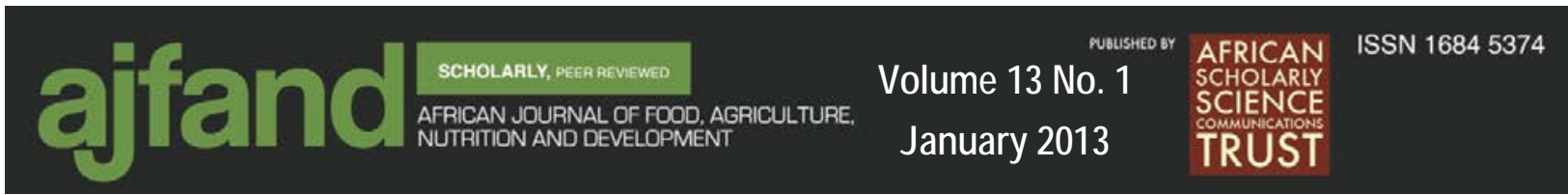

Table 4: Similarity matrix among 42 Kenyan papaya accessions

\begin{tabular}{|c|c|c|c|c|c|c|c|c|c|c|c|c|c|c|c|c|c|c|c|c|c|}
\hline & JKU1 & KIZ4 & MUT & KIZ3 & IMA1 & CHP2 & KOS1 & THK1 & MF1 & IMA6 & THK2 & VOI1 & MIG9 & IMA2 & MIG2 & KIB1 & IMA8 & VB2 & KOS2 & MIG6 & ST2 \\
\hline JKU1 & 1.000 & & & & & & & & & & & & & & & & & & & & \\
\hline KIZ4 & 0.919 & 1.000 & & & & & & & & & & & & & & & & & & & \\
\hline MUT & 0.838 & 0.838 & 1.000 & & & & & & & & & & & & & & & & & & \\
\hline KIZ3 & 0.892 & 0.919 & 0.851 & 1.000 & & & & & & & & & & & & & & & & & \\
\hline IMA1 & 0.811 & 0.838 & 0.811 & 0.851 & 1.000 & & & & & & & & & & & & & & & & \\
\hline CHP2 & 0.824 & 0.824 & 0.824 & 0.838 & 0.838 & 1.000 & & & & & & & & & & & & & & & \\
\hline KOS1 & 0.838 & 0.824 & 0.824 & 0.851 & 0.838 & 0.851 & 1.000 & & & & & & & & & & & & & & \\
\hline THK1 & 0.811 & 0.797 & 0.838 & 0.824 & 0.797 & 0.878 & 0.838 & 1.000 & & & & & & & & & & & & & \\
\hline MF1 & 0.838 & 0.824 & 0.838 & 0.851 & 0.838 & 0.838 & 0.892 & 0.851 & 1.000 & & & & & & & & & & & & \\
\hline IMA6 & 0.892 & 0.865 & 0.851 & 0.851 & 0.797 & 0.838 & 0.838 & 0.851 & 0.838 & 1.000 & & & & & & & & & & & \\
\hline THK2 & 0.851 & 0.851 & 0.865 & 0.851 & 0.824 & 0.851 & 0.811 & 0.824 & 0.838 & 0.851 & 1.000 & & & & & & & & & & \\
\hline VOI1 & 0.858 & 0.845 & 0.858 & 0.845 & 0.818 & 0.899 & 0.818 & 0.845 & 0.845 & 0.858 & 0.872 & 1.000 & & & & & & & & & \\
\hline MIG9 & 0.851 & 0.851 & 0.824 & 0.878 & 0.811 & 0.878 & 0.811 & 0.838 & 0.811 & 0.865 & 0.851 & 0.872 & 1.000 & & & & & & & & \\
\hline IMA2 & 0.845 & 0.831 & 0.872 & 0.845 & 0.791 & 0.831 & 0.831 & 0.872 & 0.858 & 0.885 & 0.818 & 0.851 & 0.845 & 1.000 & & & & & & & \\
\hline MIG2 & 0.851 & 0.865 & 0.878 & 0.878 & 0.824 & 0.851 & 0.838 & 0.865 & 0.865 & 0.905 & 0.865 & 0.872 & 0.865 & 0.912 & 1.000 & & & & & & \\
\hline KIB1 & 0.851 & 0.865 & 0.824 & 0.865 & 0.824 & 0.838 & 0.878 & 0.811 & 0.838 & 0.824 & 0.824 & 0.845 & 0.824 & 0.845 & 0.865 & 1.000 & & & & & \\
\hline IMA8 & 0.824 & 0.851 & 0.838 & 0.865 & 0.824 & 0.811 & 0.811 & 0.811 & 0.824 & 0.865 & 0.797 & 0.831 & 0.851 & 0.831 & 0.851 & 0.838 & 1.000 & & & & \\
\hline VB2 & 0.838 & 0.824 & 0.838 & 0.851 & 0.838 & 0.824 & 0.811 & 0.824 & 0.811 & 0.865 & 0.838 & 0.831 & 0.878 & 0.845 & 0.851 & 0.811 & 0.865 & 1.000 & & & \\
\hline KOS2 & 0.831 & 0.804 & 0.831 & 0.804 & 0.831 & 0.872 & 0.831 & 0.845 & 0.831 & 0.845 & 0.872 & 0.878 & 0.831 & 0.811 & 0.831 & 0.804 & 0.777 & 0.831 & 1.000 & & \\
\hline MIG6 & 0.885 & 0.858 & 0.845 & 0.885 & 0.791 & 0.818 & 0.804 & 0.791 & 0.804 & 0.858 & 0.831 & 0.851 & 0.872 & 0.865 & 0.845 & 0.845 & 0.831 & 0.845 & 0.811 & 1.000 & \\
\hline ST2 & 0.824 & 0.824 & 0.851 & 0.824 & 0.824 & 0.838 & 0.838 & 0.851 & 0.892 & 0.838 & 0.878 & 0.872 & 0.851 & 0.858 & 0.878 & 0.851 & 0.824 & 0.824 & 0.845 & 0.804 & 1.000 \\
\hline MIG1 & 0.892 & 0.865 & 0.838 & 0.851 & 0.824 & 0.878 & 0.838 & 0.865 & 0.851 & 0.932 & 0.878 & 0.899 & 0.851 & 0.858 & 0.878 & 0.824 & 0.824 & 0.838 & 0.885 & 0.845 & 0.865 \\
\hline MAN2 & 0.878 & 0.919 & 0.865 & 0.905 & 0.824 & 0.824 & 0.824 & 0.824 & 0.851 & 0.878 & 0.865 & 0.858 & 0.865 & 0.885 & 0.905 & 0.865 & 0.865 & 0.838 & 0.818 & 0.899 & 0.851 \\
\hline ST1 & 0.824 & 0.838 & 0.878 & 0.851 & 0.824 & 0.851 & 0.865 & 0.865 & 0.865 & 0.838 & 0.865 & 0.885 & 0.838 & 0.885 & 0.905 & 0.905 & 0.838 & 0.824 & 0.831 & 0.818 & 0.892 \\
\hline KOS3 & 0.791 & 0.791 & 0.777 & 0.777 & 0.764 & 0.818 & 0.777 & 0.804 & 0.791 & 0.791 & 0.791 & 0.784 & 0.804 & 0.797 & 0.804 & 0.804 & 0.777 & 0.804 & 0.784 & 0.797 & 0.791 \\
\hline EMB1 & 0.838 & 0.838 & 0.811 & 0.851 & 0.824 & 0.878 & 0.851 & 0.851 & 0.851 & 0.838 & 0.824 & 0.831 & 0.851 & 0.804 & 0.811 & 0.811 & 0.811 & 0.851 & 0.845 & 0.818 & 0.838 \\
\hline IMA7 & 0.838 & 0.824 & 0.811 & 0.797 & 0.797 & 0.811 & 0.811 & 0.838 & 0.838 & 0.838 & 0.824 & 0.831 & 0.811 & 0.845 & 0.851 & 0.838 & 0.797 & 0.797 & 0.804 & 0.804 & 0.865 \\
\hline KOS4 & 0.878 & 0.892 & 0.851 & 0.892 & 0.824 & 0.851 & 0.851 & 0.824 & 0.865 & 0.865 & 0.824 & 0.872 & 0.851 & 0.872 & 0.892 & 0.865 & 0.851 & 0.838 & 0.818 & 0.858 & 0.865 \\
\hline CHP1 & 0.851 & 0.865 & 0.865 & 0.878 & 0.811 & 0.851 & 0.824 & 0.811 & 0.811 & 0.851 & 0.865 & 0.858 & 0.865 & 0.831 & 0.865 & 0.838 & 0.824 & 0.838 & 0.845 & 0.858 & 0.811 \\
\hline MRGK2 & 0.845 & 0.872 & 0.804 & 0.885 & 0.845 & 0.831 & 0.818 & 0.831 & 0.818 & 0.818 & 0.845 & 0.838 & 0.831 & 0.797 & 0.831 & 0.845 & 0.818 & 0.845 & 0.811 & 0.811 & 0.858 \\
\hline JKU3 & 0.838 & 0.838 & 0.865 & 0.824 & 0.851 & 0.851 & 0.838 & 0.824 & 0.865 & 0.851 & 0.838 & 0.858 & 0.811 & 0.831 & 0.865 & 0.838 & 0.824 & 0.811 & 0.845 & 0.804 & 0.865 \\
\hline MF1 & 0.838 & 0.838 & 0.838 & 0.838 & 0.838 & 0.824 & 0.838 & 0.838 & 0.865 & 0.838 & 0.851 & 0.858 & 0.824 & 0.818 & 0.838 & 0.838 & 0.838 & 0.824 & 0.818 & 0.804 & 0.878 \\
\hline MF2 & 0.851 & 0.851 & 0.851 & 0.851 & 0.838 & 0.838 & 0.838 & 0.865 & 0.878 & 0.851 & 0.878 & 0.858 & 0.838 & 0.845 & 0.865 & 0.824 & 0.811 & 0.824 & 0.845 & 0.831 & 0.905 \\
\hline JKU2 & 0.838 & 0.878 & 0.865 & 0.932 & 0.838 & 0.892 & 0.865 & 0.878 & 0.865 & 0.865 & 0.851 & 0.872 & 0.892 & 0.885 & 0.905 & 0.865 & 0.865 & 0.851 & 0.818 & 0.858 & 0.851 \\
\hline PKR1 & 0.838 & 0.851 & 0.824 & 0.838 & 0.811 & 0.905 & 0.865 & 0.865 & 0.851 & 0.865 & 0.838 & 0.845 & 0.865 & 0.872 & 0.865 & 0.851 & 0.824 & 0.824 & 0.831 & 0.831 & 0.851 \\
\hline RAP1 & 0.824 & 0.824 & 0.838 & 0.865 & 0.797 & 0.892 & 0.851 & 0.851 & 0.865 & 0.838 & 0.824 & 0.831 & 0.892 & 0.845 & 0.824 & 0.824 & 0.824 & 0.838 & 0.804 & 0.831 & 0.811 \\
\hline KLF1 & 0.878 & 0.865 & 0.851 & 0.851 & 0.838 & 0.838 & 0.824 & 0.797 & 0.811 & 0.865 & 0.865 & 0.845 & 0.838 & 0.858 & 0.851 & 0.824 & 0.824 & 0.851 & 0.858 & 0.872 & 0.824 \\
\hline KLF2 & 0.892 & 0.878 & 0.865 & 0.878 & 0.811 & 0.878 & 0.811 & 0.865 & 0.824 & 0.919 & 0.878 & 0.885 & 0.919 & 0.872 & 0.892 & 0.824 & 0.865 & 0.878 & 0.858 & 0.885 & 0.838 \\
\hline IMA5 & 0.851 & 0.838 & 0.838 & 0.865 & 0.851 & 0.851 & 0.838 & 0.824 & 0.851 & 0.851 & 0.892 & 0.885 & 0.878 & 0.818 & 0.824 & 0.811 & 0.811 & 0.851 & 0.912 & 0.858 & 0.851 \\
\hline MIG4 & 0.797 & 0.797 & 0.811 & 0.784 & 0.770 & 0.824 & 0.784 & 0.824 & 0.811 & 0.811 & 0.824 & 0.804 & 0.797 & 0.791 & 0.811 & 0.811 & 0.797 & 0.784 & 0.804 & 0.791 & 0.824 \\
\hline PKR4 & 0.838 & 0.838 & 0.851 & 0.851 & 0.851 & 0.892 & 0.851 & 0.905 & 0.905 & 0.865 & 0.865 & 0.885 & 0.838 & 0.872 & 0.905 & 0.838 & 0.824 & 0.824 & 0.858 & 0.804 & 0.892 \\
\hline VB1 & 0.865 & 0.851 & 0.838 & 0.865 & 0.824 & 0.851 & 0.838 & 0.838 & 0.838 & 0.865 & 0.865 & 0.845 & 0.838 & 0.818 & 0.811 & 0.811 & 0.824 & 0.824 & 0.872 & 0.845 & 0.824 \\
\hline
\end{tabular}




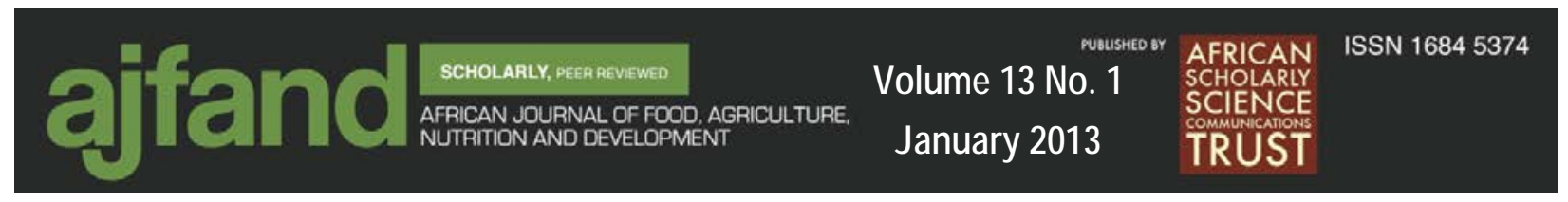

\begin{tabular}{|c|c|c|c|c|c|c|c|c|c|c|c|c|c|c|c|c|c|c|c|c|c|}
\hline & MIG1 & MAN2 & ST1 & KOS3 & EMB1 & IMA7 & KOS4 & CHP1 & MRGK2 & JKU3 & MF1 & MF2 & JKU2 & PKR1 & RAP1 & KLF1 & KLF2 & IMA5 & MIG4 & PKR4 & VB1 \\
\hline MIG1 & 1.000 & & & & & & & & & & & & & & & & & & & & \\
\hline MAN2 & 0.865 & 1.000 & & & & & & & & & & & & & & & & & & & \\
\hline ST1 & 0.851 & 0.851 & 1.000 & & & & & & & & & & & & & & & & & & \\
\hline KOS3 & 0.804 & 0.804 & 0.791 & 1.000 & & & & & & & & & & & & & & & & & \\
\hline EMB1 & 0.851 & 0.824 & 0.811 & 0.831 & 1.000 & & & & & & & & & & & & & & & & \\
\hline IMA7 & 0.851 & 0.865 & 0.838 & 0.831 & 0.824 & 1.000 & & & & & & & & & & & & & & & \\
\hline KOS4 & 0.838 & 0.905 & 0.865 & 0.804 & 0.851 & 0.878 & 1.000 & & & & & & & & & & & & & & \\
\hline CHP1 & 0.865 & 0.878 & 0.851 & 0.804 & 0.838 & 0.824 & 0.851 & 1.000 & & & & & & & & & & & & & \\
\hline MRGK2 & 0.845 & 0.831 & 0.845 & 0.797 & 0.858 & 0.804 & 0.831 & 0.818 & 1.000 & & & & & & & & & & & & \\
\hline JKU3 & 0.865 & 0.838 & 0.851 & 0.791 & 0.838 & 0.838 & 0.865 & 0.838 & 0.818 & 1.000 & & & & & & & & & & & \\
\hline MF1 & 0.838 & 0.824 & 0.865 & 0.777 & 0.838 & 0.838 & 0.851 & 0.824 & 0.845 & 0.851 & 1.000 & & & & & & & & & & \\
\hline MF2 & 0.878 & 0.878 & 0.851 & 0.791 & 0.865 & 0.851 & 0.851 & 0.811 & 0.885 & 0.851 & 0.865 & 1.000 & & & & & & & & & \\
\hline JKU2 & 0.851 & 0.905 & 0.892 & 0.777 & 0.851 & 0.797 & 0.892 & 0.851 & 0.858 & 0.838 & 0.824 & 0.865 & 1.000 & & & & & & & & \\
\hline PKR1 & 0.865 & 0.851 & 0.851 & 0.804 & 0.851 & 0.838 & 0.851 & 0.838 & 0.831 & 0.838 & 0.811 & 0.851 & 0.878 & 1.000 & & & & & & & \\
\hline RAP1 & 0.824 & 0.824 & 0.824 & 0.818 & 0.878 & 0.797 & 0.851 & 0.851 & 0.804 & 0.824 & 0.838 & 0.811 & 0.878 & 0.878 & 1.000 & & & & & & \\
\hline KLF1 & 0.851 & 0.892 & 0.824 & 0.804 & 0.838 & 0.865 & 0.892 & 0.851 & 0.831 & 0.824 & 0.824 & 0.851 & 0.838 & 0.865 & 0.824 & 1.000 & & & & & \\
\hline KLF2 & 0.905 & 0.892 & 0.865 & 0.804 & 0.851 & 0.811 & 0.851 & 0.892 & 0.845 & 0.838 & 0.824 & 0.851 & 0.905 & 0.878 & 0.851 & 0.878 & 1.000 & & & & \\
\hline IMA5 & 0.892 & 0.851 & 0.838 & 0.777 & 0.865 & 0.797 & 0.811 & 0.865 & 0.831 & 0.851 & 0.824 & 0.865 & 0.865 & 0.824 & 0.824 & 0.851 & 0.892 & 1.000 & & & \\
\hline MIG4 & 0.811 & 0.824 & 0.824 & 0.845 & 0.811 & 0.838 & 0.824 & 0.838 & 0.777 & 0.797 & 0.797 & 0.797 & 0.797 & 0.811 & 0.811 & 0.811 & 0.838 & 0.797 & 1.000 & & \\
\hline PKR4 & 0.892 & 0.865 & 0.878 & 0.791 & 0.851 & 0.838 & 0.865 & 0.838 & 0.845 & 0.892 & 0.851 & 0.892 & 0.892 & 0.878 & 0.824 & 0.824 & 0.878 & 0.865 & 0.811 & 1.00 & \\
\hline VB1 & 0.892 & 0.851 & 0.824 & 0.791 & 0.865 & 0.811 & 0.824 & 0.878 & 0.818 & 0.838 & 0.851 & 0.851 & 0.838 & 0.824 & 0.851 & 0.851 & 0.865 & 0.905 & 0.838 & 0.838 & 1.00 \\
\hline
\end{tabular}

The similarity coefficients generated using (SIMQUAL) similarity for qualitative data

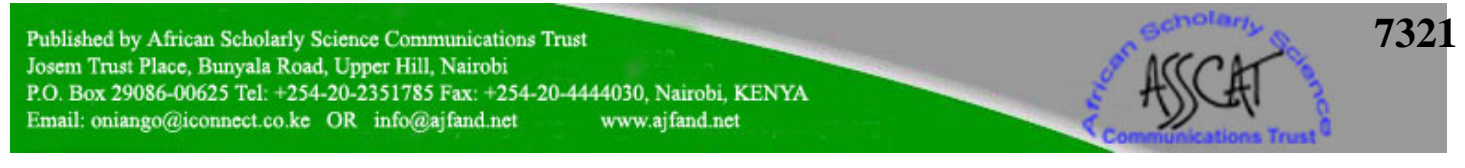




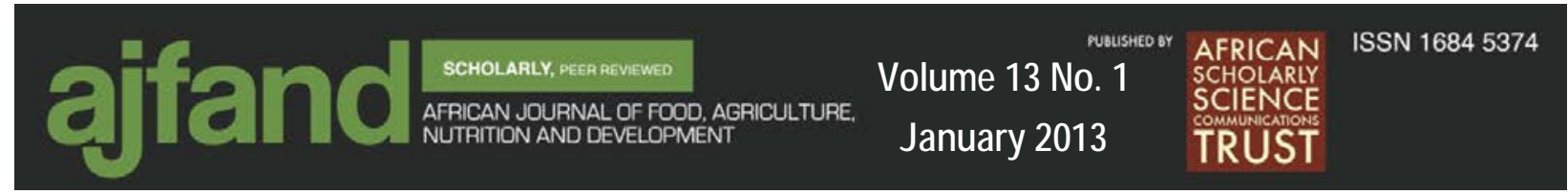

\section{REFERENCES}

1. Villegas VN Carica papaya L. In: Verheij EWM and RE Coronel (Eds). Edible fruits and nuts, Wageningen University, Netherlands, 1997: 2.

2. Food and Agricultural Organization (FAO), Statistical databases of the Food and Agriculture Organization of the United Nations. http://apps.fao.org, 2009.

3. Imungi JK and MN Wabule Some chemical characteristics and availability of vitamin A and C from Kenyan varieties of papaya (Carica papaya L.). Ecol. Food Nutri. 1990; 24: 115-120.

4. Horticultural Crops Development Authority (HCDA) Annual report, Horticultural Crops Development Authority. Nairobi, Kenya, 2009.

5. Asudi GO Collection, morphological and molecular characterization of Kenyan Papaya Germplasm, Jomo Kenyatta University of Agriculture and Technology, Nairobi, Kenya, Thesis. 2010: 27-41.

6. Magdalita PM, Laurena AC, Yabut-Perez BM, Tecson-Mendoza EM, Villegas VN and JR Botella Progress in the Development of Transgenic Papaya: Transformation of Solo Papaya using ACC Synthase Antisense Construct. Proc. Trop. Subtrop. Fruits Acta. Hort. (2002); 575 ISHS.

7. Office of the Gene Technology Regulator (OGTR) The biology of Carica papaya L. (papaya, papaw, paw paw). Australian Government Department of Health and Ageing. Retrieved October 19, 2009, from http://www.ogtr.gov.au. 2008: 2:1-55.

8. Ocampo JP, d'Eeckenbrugge GC, Bruyère $S$, DE Bellaire LL and $P$ Ollitrault Organization of morphological and genetic diversity of Caribbean and Venezuelan papaya germplasm. Fruits. 2006; 61: 25-37.

9. Weising $\mathbf{K}$, Nybom $\mathbf{H}$, Wolff $\mathbf{K}$ and Kahl $\mathbf{G}$ DNA fingerprinting in plants: principles, methods, and applications ( $2^{\text {nd }}$ Ed). CRC Press, London. 2005.

10. Asudi GO, Ombwara FK, Rimberia FK, Nyende AB, Ateka EM, Wamocho LS, Shitanda $D$ and A Onyango Morphological diversity of Kenyan papaya germplasm. Afr. J. Biotechnol. 2010; 9 (51): 8754-8762.

11. Ocampo JP, Dambier D, Ollitrault P, d'Eeckenbrugge GC, Brottier P, Froelicher Y, and A Risterucci Microsatellite markers in Carica papaya L.: Isolation, characterization and transferability to Vasconcellea species. Mol. Ecol. Notes. 2006; 6: 212-217.

12. Doyle JJ and JT Doyle A rapid total DNA preparation procedure for fresh plant tissues. Focus 1990; 19: 11-15. 
13. International Maize and Wheat Improvement Center (CIMMYT) Laboratory Protocols, CIMMYT Applied Molecular Genetics Laboratory ( $3^{\text {rd }}$ Ed). Mexico, D.F: CIMMYT. 2005.

14. Applied Biosystems Microsatellite analysis on the Applied Biosystems 3130 Series Genetic Analyzers, Applied Biosystems. Retrieved September 10, 2009, from http://www.appliedbiosystems.com. 2004.

15. Rohlf FJ NTSYS-pc: Numerical taxonomy and multivariate analysis system. Applied Biostatistics, Exerter Publishing Ltd., New York, 2000.

16. Sakiyama NS DNA markers for coffee tree breeding. In: Sera T, Soccol CR, Pandy A and S Roussos (Eds) Coffee biotechnology and quality, Kluwer Academic Publishers, Dordrecht, 2000:179-185.

17. Bligh HFJ, Blackhall NW, Edwards KY and AM McClung Using amplified length polymorphism to identify cultivars of brown and white milled rice. Crop. Sci. 1999; Зa (6): 1715-1721.

18. Di-Gaspero G, Peterlunger E, Testolin R, Edwards KJ and G Clipriani Conservation of microsatellite loci within the genus Vitis. Theor. Appl. Genet. 2000; 101: 303-308.

19. Yu JK, Mangot J, Thompson L, Edwards KJ, Slabaugh MB and SJ Knapp Allelic diversity of simple sequence repeats among elite inbred lines of cultivated sunflower, Genome. 2000; 45: 652-660.

20. Danin-Poleg Y, Reis N, Baudraci S, Arnas S, Pitrat M, Staub JE, Oliver M, Arus P, Devicente $\mathbf{C M}$ and $\mathbf{N}$ Katzir Simple sequence repeats in cucumis mapping and map margin, Genet. 2001; 43: 963-974.

21. Moyib OK, Odunola OA and AGO Dixon SSR markers reveal genetic variation between improved cassava cultivars and landraces within a collection of Nigerian cassava germplasm. Afr. J. Biotechnol. 2007; 6(23): 2666-2674.

22. Karuri HW, Ateka EM, Amata $R$, Nyende AB and AWT Muigai Characterization of Kenyan sweet potato genotypes for SPVD resistance and high dry matter content using simple sequence repeat markers Afr. J. Biotechnol. 2009; 8(10): 2169-2175.

23. Kim MS, Moore PH, Zee F, Fitch MMM, Steiger DL, Manshardt RM, Paull RE, Drew RA, Sekioka $\mathbf{T}$ and $\mathbf{R}$ Ming Genetic diversity of Carica papaya as revealed by AFLP markers. Genome. 2002; 45: 503-512.

24. Hofmyer JDJ Some genetic and breeding aspects of Carica papaya. Agron. Trop. 1967; 17: 345-351.

25. Storey WB Papaya. In: Simmonds NW (Ed). Evolution of crop plants. Longman, London. 1976: 21-24. 
26. Arumuganathan K and ED Earle Nuclear DNA content of some important plant species. Plant. Mol. Biol. Reporter, 1991; 9: 208-218.

27. Storey WB Segregations of sex types in solo papaya and their application to the selection of seed. Proc. Amer. Soc. Hort. Sci. 1938; 35: 83-85.

28. Hofmyer JDJ Genetic studies of Carica papaya L. S. Afri. J. Sci. 1938; 35: 300-304.

29. Camussi A, Ottaviano E, Calinski T and Z Kaczmarek Genetic distances based on quantitative traits, Genet. 1985; 111: 945-962. 